\title{
IMPACTO DE LA INFRAESTRUCTURA VIAL Y DE LAS EXPORTACIONES SOBRE EL CRECIMIENTO ECONÓMICO REGIONAL: CASO DE LA REGIÓN ÁNCASH
}

\section{IMPACT OF ROAD INFRASTRUCTURE AND EXPORTS ON REGIONAL ECONOMIC GROWTH: CASE OF THE ANCASH REGION}

\author{
Alejandro De La Cruz Pairazamán Rodas \\ Economista, Universidad Nacional Mayor de San Marcos, Lima, Perú. Email: janorodas@hotmail.com (Autor Corresponsal)
}

[Recibido: 09/03/2016 Aceptado: 18/08/2017]

\section{RESUMEN}

Esta investigación evalúa el impacto de la calidad de la infraestructura vial y de las exportaciones sobre el crecimiento económico en la región Áncash en el periodo 2003-2013; estudia cómo la calidad de la infraestructura vial ha impactado sobre la localización territorial de las industrias exportadoras, sobre la bancarización regional, y de qué manera éstas han impactado sobre el crecimiento económico de la región; finalmente analiza el impacto del crecimiento económico sobre el nivel de pobreza en dicha región. Las empresas exportadoras extractivas de la región se ubican donde se localizan sus recursos naturales (yacimientos mineros y anchoveta); las agroexportadoras de frutas y hortalizas se localizan en la costa de la región, mientras que no existe ninguna agroexportadora en el Callejón de Conchucos debido a la carencia de la infraestructura vial mínima que haga rentable el negocio; el estudio revela que la región tiene un sistema financiero primario y desigual debido a que varias provincias no cuentan con oficinas bancarias. A pesar de que el PBI de la región solo creció a una tasa anual del $0,8 \%$ en el período 2007-2014, la pobreza total ha tenido una significativa reducción, pero muy desigual.

\section{PALABRAS CLAVE}

Infraestructura vial, exportaciones, crecimiento económico, finanzas, Áncash.

\begin{abstract}
This research evaluates the impact of the road infrastructure and exports quality on economic growth in the Ancash region in the period 2003-2013; it studies how the road infrastructure quality has impacted the territorial location of export industries, regional bancarization, and how these have impacted on the economic growth of the region; finally, it analyzes the impact of economic growth on the level of poverty in that region. The regional extractive exporting companies are placed where their natural resources are located (mining deposits and anchovy); the agriexporters of fruits and vegetables are positioned on the region's coast, while there is no agriexport in the Callejon de Conchucos due to the lack of minimal road infrastructure that makes the business profitable. The study reveals that the region has a primary and unequal financial system because several provinces do not have bank offices. Despite the fact that the GDP of the region only grew at an annual rate of $0.8 \%$ in the $2007-2014$ period, total poverty has had a significant reduction, but very disparate.
\end{abstract}

\section{KEYWORDS}

Road infrastructure, exports, economic growth, finance, Ancash.

Como Citar: Pairazamán, A. (2017). Impacto de la infraestructura vial y de las exportaciones sobre el crecimiento económico regional: caso de la región Áncash. Quipukamayoc, 25(49), 41-49 . doi: http://dx.doi.org/10.15381/quipu.v25i49.14278 


\section{INTRODUCCIÓN}

El objetivo del trabajo de investigación es analizar la Infraestructura vial de la Región Áncash y su rol en el cre- cimiento económico de dicha región. Nos interesa evaluar el impacto de la disponibilidad o carencia de la infraestructura vial sobre el desarrollo de las exportaciones, de las finanzas $y$ finalmente sobre el crecimiento económico y de pobreza en la región Áncash.

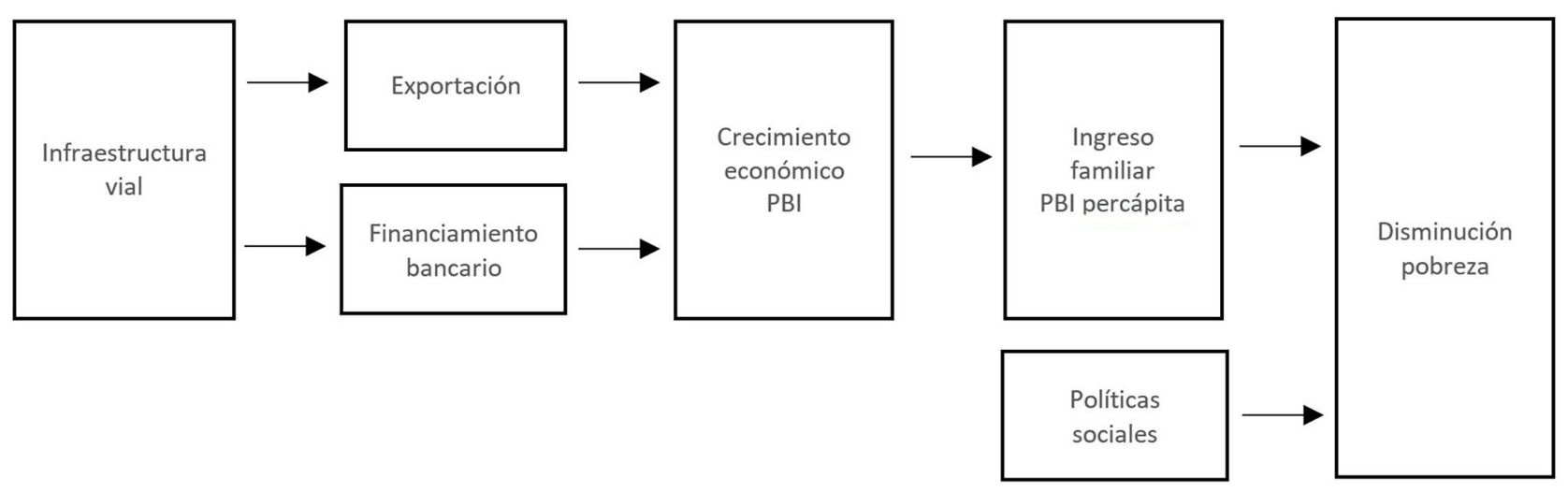

Figura 1. Impacto de la infraestructura vial y de las exportaciones sobre el crecimiento económico regional: Caso de la Región Áncash

Fuente: Elaboración propia

García y Céspedes (2011) refieren "El crecimiento económico es condición necesaria para el desarrollo económico y la reducción de la pobreza" (p.2).

En el caso del Perú la economía logro un crecimiento a lo largo de las dos décadas posteriores a 1990. En el documento se estudia la relación empírica entre pobreza y crecimiento económico durante la primera década del presente siglo, la economía peruana creció 55\% y al mismo tiempo una reducción de los indicadores de pobreza y de desigualdad en la distribución del ingreso, la pobreza total se redujo en $43 \%$, la pobreza extrema en $60 \%$, y el coeficiente Gini, como indicador de la desigualdad en la distribución del ingreso, en el País el Índice fue de 0,507 en el 2010.

A continuación plantearemos algunas definiciones referidas a las variables económicas y variables sociales: Infraestructura vial, exportaciones, crecimiento económico, finanzas, pobreza

\section{Infraestructura Vial}

La infraestructura vial es el conjunto de componentes físicos que interrelacionados entre sí de manera coherente y bajo cumplimiento de ciertas especificaciones técnicas de diseño y construcción, ofrecen condiciones cómodas y seguras para la circulación de vehículos y personas en forma cómoda. Asimismo constituyen uno de los pilares de crecimiento y desarrollo sostenible del país. Pese a su importancia económica y social, en el Perú hay una brecha de infraestructura estimada en $\$ 87985$ millones.

\section{Comercio Internacional}

Con la finalidad de conocer los orígenes y la importancia del comercio internacional, nos remontamos a Smith (1776) que plantea ideas acerca de la lógica del comercio tanto entre personas como entre países; esta lógica se basa en la conveniencia de especializarse en la producción de lo que un país puede producir más económica- mente para comerciar con otros países para el beneficio de los dos; esto significa utilizar la clásica división del trabajo, dependiendo de las diferencias de capital, trabajadores y recursos naturales.

Ricardo (1817) precisa sobre el análisis de Adam Smith al demostrar que el comercio internacional mutuamente beneficioso es posible aun cuando solamente existan ventajas comparativas es decir los países tienden a especializarse en la producción y exportación de aquellos bienes que fabrican a un costo relativamente más bajo respecto al resto del mundo., llegando a la conclusión de que las ventajas absolutas constituyen un caso especial de un principio más general que es el de las ventajas comparativas; el punto de partida de la explicación que da Ricardo se basa en la teoría del valor-trabajo; al respecto, según Ricardo, la regla que rige el valor relativo de los bienes al interior de un país, no es la misma que regula el valor relativo de los productos intercambiados 
entre dos o más países; según Ricardo, es el costo del trabajo relativo o comparativo de las mercancías en cada país, en lugar de los costos absolutos, lo que determina el valor en los intercambios internacionales.

Ohlin (1966) desarrolla el modelo matemático de comercio internacional que puso énfasis en la ventaja que logran los países por contar con una fuerte dotación de algunos de los factores de producción como en materias primas, fuerza laboral o capital; algunos ejemplos de este modelo lo constituyen la ventaja del Oriente medio en petróleo y de la china e India en fuerza laboral relativamente barata; este modelo parte de la teoría sobre la ventaja comparativa y afirma que los países se especializan en la exportación de los bienes cuya producción es intensiva en el factor en el que el país es abundante, mientras que tienden a importar aquellos bienes que utilizan de forma intensiva el factor que es relativamente escaso en dicho país.

Respecto al capital, Argandoña (2007) plantea:

Por capital entendemos el stock de bienes producidos que se emplean para producir otros bienes y servicios: máquinas, fábricas, camiones, tractores, instalaciones, stocks de materias primas y de productos en curso, etc., incluyendo el capital productivo de propiedad pública como carreteras, ferrocarriles, puertos, aeropuertos, represas (p. 21-22).

Respecto de las características de la pobreza, Nuñovero (2011), precisa que:

En consecuencia, los especialistas del desarrollo han empezado a trabajar en base a un concepto multidimensional de pobreza, interrelacionado aspectos económicos (ingresos, poder adquisitivo, etc.). Sociales (empleo, nivel educativo, etc.), políticos (participación, derechos, etc.) e incluso culturales como las creencias o los idiomas y medioambientales como la degradación medioambiental (p.3).

García (2017) como vocero de la Comisión Económica para América Latina y el Caribe, explica que la desigualdad es un problema que se busca reducir desde hace más de 10 años y que es una de las brechas estructurales más importantes que impiden el desarrollo de la Región de América Latina y el Caribe en su conjunto y los países que la conforman, incluyendo Perú. Asimismo, refiere que se vienen trabajando las desigualdades cruzadas, en donde la matriz de las desigualdades tiene muchos componentes; entre ellas, las productivas, las tecnológicas, de género y de etnia. Agregó que la desigualdad también se observa cuando, por ejemplo, no se ofrece un empleo de calidad, lo cual impide que las personas puedan acceder a toda una serie de servicios, como protección social, salud y pensiones, los cuales son importantes para todo el ciclo de vida

Respecto al desarrollo económico, Schumpeter (1946) sostiene que es un fenómeno característico totalmente diferente a lo que puede ser observado en la corriente circular o en la tendencia al equilibrio. Es un cambio espontáneo y discontinuo en los cauces de la corriente, alteraciones del equilibrio que desplazan para siempre el estado de equilibrio existente con anterioridad. Nuestra teoría del desarrollo no es sino el estudio de este fenómeno y los procesos que le acompañan.

\section{Exportación}

En economía una exportación es cualquier bien o servicio enviado fuera del territorio nacional; la exportación es el tráfico legítimo de bienes y/o servicios desde un territorio aduanero hacia otro territorio aduanero; las exportaciones pueden ser cualquier producto enviado fuera de la frontera aduanera de un Estado o bloque económico; las exportaciones son generalmente llevadas a cabo bajo condiciones específicas.

\section{Bancarización}

Término que hace referencia al grado de utilización de los productos y servicios bancarios, esto es de la red bancaria, por parte de la población de una economía, o bien un determinado segmento de la misma o sector económico concreto; es uno de los indicadores de la cultura financiera de un país; la bancarización se refiere al establecimiento de relaciones estables y amplias entre las instituciones financieras y sus usuarios, respecto de un conjunto de servicios financieros disponibles.

Generalmente se identifica el crecimiento económico y los factores que inciden en él con los aspectos reales de la economía: la producción, empleo, tecnología, sin tomar en cuenta a los aspectos financieros. Sin embargo en los países desarrollados hay una alta relación entre crecimiento económico y desarrollo de las finanzas.

El sector financiero de la economía de un país o de una región particular puede ser a la vez, causa y consecuencia del grado de crecimiento económico de ese país o región; al 
respecto, mientras más pobre sea el área en consideración, probablemente su sector financiero se caracterice por su atraso relativo; de aquí que una de las posibles estrategias de crecimiento económico se base en el desarrollo de las variables financieras, para tratar de facilitar de ese modo el crecimiento de las variables reales; en el caso del presente trabajo se quiere demostrar que la carencia de una infraestructura vial adecuada dificulta o anula el desarrollo financiero de una determinada región.

\section{Crecimiento económico}

A grandes rasgos, el crecimiento económico se refiere al incremento de ciertos indicadores, como la producción de bienes y servicios, el mayor consumo de energía, el ahorro, la inversión, una balanza comercial favorable, el aumento de consumo de calorías per cápita, etc. La mejora de estos indicadores debería llevar teóricamente a un alza en los estándares de vida de la población.

Habitualmente el crecimiento económico se mide en porcentaje de aumento del Producto Interno Bruto real o PIB; y se asocia a la productividad. El crecimiento económico, así definido, se ha considerado(históricamente) deseable, porque guarda una cierta relación con la cantidad de bienes materiales disponibles y por ende una cierta mejora del nivel de vida de las personas, sin embargo algunos autores han señalado que el crecimiento económico depende del PIB per cápita, es decir el ingreso de los habitantes de un país.

\section{Pobreza}

La pobreza es la situación socioeconómica de la población que no puede acceder o carece de los recursos para satisfacer sus necesidades físicas y psíquicas básicas que le permitan una adecuada calidad de vida referidas a la alimentación, la vivienda, la educación, la asistencia sanitaria o el acceso al agua potable; se podría considerar como causa de la pobreza al desempleo o subempleo que da lugar a la falta de ingresos que le impiden satisfacer sus necesidades básicas; asimismo, la pobreza puede ser el resultado de procesos de exclusión social, segregación social o marginación; en muchos países del tercer mundo, la situación de pobreza se presenta cuando no es posible cubrir las necesidades incluidas en la canasta básica de alimentos.

La medición de la pobreza: En el Perú se usa el método de "Líneas de la pobreza monetaria”. El Ministerio de Economía y Finanzas (MEF) define la pobreza monetaria como la insuficiencia de recursos monetarios para adquirir una canasta de consumo mínima aceptable socialmente. En términos simples, pobre es aquel que no tiene el dinero para comprar la canasta mencionada.

Una línea de la pobreza es un límite o umbral, que indica el costo (expresado en unidades monetarias) de la canasta mencionada, Aquellos cuya capacidad de gasto es menor que la línea son considerados pobres; por el contrario los que pueden un monto mayor que el indicado por la línea son considerados no pobres. En otras palabras, la línea de la pobreza divide a la población en dos grupos: pobres y no pobres.

\section{MATERIAL Y MÉTODOS}

La investigación es de carácter explicativo-causal porque se estudia la evolución e interrelación de las diversas variables, tanto micro como ma- croeconómicas, reales y financieras, relacionadas con las exportaciones, la banca, el crecimiento económico regional y la pobreza en la región Áncash durante el período 2003-2014, teniendo como eje de la investigación a la dotación de infraestructura vial en cada una de las 3 zonas en que se ha dividido la región Áncash : la costa, el Callejón de Huaylas y el Callejón de Conchucos; asimismo, esta investigación es esencialmente aplicativa toda vez que sus conclusiones y recomendaciones pretenden lograr un mayor desarrollo de las empresas exportadoras así como de la banca y por ende una mayor tasa de crecimiento económico en la región Áncash con la finalidad de alcanzar una mejora en la calidad de vida de sus pobladores así como la disminución de la pobreza.

Esta investigación es de carácter no-experimental y retrospectivo-longitudinal puesto que se sustenta en información de series históricas regionales para el periodo 2003-2014; el método para ejecutar la presente trabajo consiste en formular primero el marco teórico necesario para un adecuado conocimiento e interpretación de la geografía económica reflejada en la dotación de infraestructura vial en cada una de las 3 zonas de la región Áncash a fin de evaluar su impacto sobre las exportaciones FOB y la banca, y la de éstas sobre el crecimiento económico en la región Áncash y su pobreza, para enseguida comenzar a recopilar información de origen secundario correspondiente al periodo 2003-2014 sobre las variables e indicadores pertinentes.

La unidad de análisis en este estudio es la región Áncash dentro de la cual se analiza las causas de su situación de pobreza mediante la utilización de diversos indicadores dentro de los cuales destaca la dotación de infraestructura vial en dicha región. 


\section{RESULTADOS}

a. Análisis de la Red Vial en la Región Áncash

La red vial nacional en la región Áncash es de 1620 kilómetros que en un 57,5\% está asfaltada (932 kilómetros) cubre 5 rutas, 3 transversales costa-sierra (norte, centro y sur) y 2 longitudinales, por la costa una y la otra por el Callejón de Huaylas; esta red vial nacional no comunica territorialmente a las ciudades del Callejón de Conchucos entre sí, ni a estas ciudades con las ciudades del Callejón de
Huaylas y menos con las ciudades de la costa ancashina; por otra parte, la red vial nacional que no está asfaltada (688 kilómetros) recorre las provincias: Huaylas, Corongo y Sihuas por el norte de la Región; Huari y Antonio Raimondi por el sur de Áncash.

De otro lado, la red vial departamental en la región Áncash de 1481 kilómetros que solamente en un 14,5\% asfaltada (215 kilómetros) cubre 5 rutas, de las cuales la ruta Catac-Huantar conecta al Callejón de Huaylas con el Callejón de Conchucos, mientras que la ruta inconclusa Huallanca-San
Marcos marcaría el inicio de la construcción de una carretera asfaltada por todo el Callejón de Conchucos; asimismo, la red vial departamental que no está asfaltada cuenta con 1266 kilómetros, de esta investigación se concluye que la red vial, tanto nacional como departamental, del Callejón de Conchucos en comparación con la red vial existente en la costa de la región Ancash o con la red vial del Callejón de Huaylas es insuficiente y de mala calidad; solamente la provincia de Huari ubicada en el Callejón de Conchucos cuenta con 83 kilómetros de carreteras asfaltadas.

Tabla 1.

Red Vial Nacional, Departamental y Vecinal: julio 2013

Fuente: Ministerio de Transportes y Comunicaciones.

\begin{tabular}{|c|c|c|c|c|c|}
\hline & \multicolumn{4}{|c|}{ Kilómetros Perú } & \multirow{2}{*}{$\begin{array}{c}\text { Ratio (\%) } \\
\text { Áncash/Perú }\end{array}$} \\
\hline & Nacional & Regional & Vecinal & Total & \\
\hline Asfaltada & 15086 & 2299 & 1627 & 19012 & \\
\hline No-pavimentada & 9857 & 22679 & 94196 & 126732 & \\
\hline Afirmada & 9857 & 14598 & 20260 & 44715 & \\
\hline No-afirmada & 0,0 & 8081 & 73936 & 82017 & \\
\hline Total & 24943 & 24978 & 95823 & 145744 & \\
\hline \multicolumn{6}{|c|}{ Kilómetros Áncash } \\
\hline & Nacional & Regional & Vecinal & Total & \\
\hline Asfaltada & 932 & 215 & 83,00 & 1230 & 6,5 \\
\hline No-pavimentada & 688 & 1266 & 6633 & 8587 & 6,8 \\
\hline Afirmada & 688 & 1256 & 1015 & 2959 & 6,6 \\
\hline No-afirmada (1) & 0,0 & 10,00 & 5618 & 5628 & 6,9 \\
\hline Total & 1620 & 1481 & 6716 & 9817 & 6,7 \\
\hline \multicolumn{6}{|c|}{ Perú \% } \\
\hline & Nacional & Regional & Vecinal & Total & \\
\hline $\begin{array}{c}\text { Asfaltada/total } \\
\text { Carreteras }\end{array}$ & 60,5 & 9,2 & 1,7 & 13,0 & \\
\hline \multicolumn{6}{|c|}{ Áncash \% } \\
\hline & Nacional & Regional & Vecinal & Total & \\
\hline $\begin{array}{c}\text { Asfaltada/total } \\
\text { Carreteras }\end{array}$ & 57,5 & 14,5 & 1,2 & 12,5 & \\
\hline
\end{tabular}


b. Análisis de las Exportaciones de la Región Áncash

El éxito económico del sudeste asiático ha convertido la promoción de exportaciones en la política fundamental de la estrategia de desarrollo de los países no industrializados; en términos generales la integración de la economía local a la internacional constituye una reforma fundamental para todos los países; al respecto, en la Región Áncash, las empresas exportadoras de tipo extractivas como las mineras y pesqueras tradicionales generalmente se ubican allí donde se localizan sus recursos naturales, es decir los yacimientos mineros y la anchoveta; en tal sentido las empresas mineras de la región Áncash se ubican en la sierra de dicha región, ya sea en el Callejón de Huaylas (Minera Barrick Misquichilca S.A, provincia de Huaraz) o en el Callejón de Conchucos (Cía. Minera Antamina SA, provincia de Huari y Cía Minera Santa Luisa SA, provincia de Bolognesi); dada la enorme magnitud de las inversiones mineras y la elevada rentabilidad del negocio, por lo general a estas empresa no les interesa si el territorio donde se ubican sus yacimientos mineros cuentan o no con la infraestructura vial adecuada; así, algunas construyen sus propias centrales hidroeléctricas, otras construyen sus propias trochas carrozables; en el caso de la Cía. Minera Antamina, ésta construyó su propio mineroducto para trasladar sus concentrados de cobre principalmente hasta el puerto de Huarmey; de la misma manera, las empresas pesqueras tradicionales productoras de harina y aceite de anchoveta tienen sus plantas procesadoras en los puertos donde sus embarcaciones realizan sus capturas de anchovetas.

Asimismo, las principales empresas agroexportadoras no-tradicionales de frutas y de hortalizas se localizan en la costa de la región Áncash, mientras que no existe ninguna empresa agroexportadora localizada en el Callejón de Conchucos debido a la carencia de la infraestructura vial mínima que haga rentable la agro exportación no-tradicional de dicha zona.

\section{c. Análisis del Sistema Financiero de la Región Áncash}

La región Áncash tenía el 2014 una colocación per cápita de S/. 2482 frente a una colocación per cápita del país de S/. 7 316; estas cifras revelan que la región Áncash tiene un sistema financiero bastante primario que es necesario desarrollar con urgencia con miras a facilitar el crecimiento económico regional; una de las razones de esta situación es el hecho de que ningún monto de crédito al sector privado es otorgado por la banca múltiple en las ciudades (provincias) del Callejón de Conchucos debido a la carencia de una infraestructura vial adecuada; asimismo, ningún monto de crédito al sector privado es otorgado por las Cajas Municipales de Ahorro y Crédito en las ciudades (provincias) del Callejón de Conchucos por la razón antes mencionada.

Justamente la mayor bancarización ocurre en las provincias de Santa (capital Chimbote) y Huaraz (capital Huaraz) que cuentan con una infraestructura vial muy superior al resto de provincias de la región Áncash.

\section{d. Análisis del impacto de las Finanzas $y$ de la Exportación sobre el PBI Re- gional}

La elasticidad-crédito al sector privado del PBI (Ecsp) para la región Áncash es 0,28, mientras que para el país es 0,52 ; estos resultados nos indican el menor impacto que han tenido las finanzas ancashinas sobre el PBI de la región Áncash en comparación con el impacto que han tenido las finanzas del país sobre el PBI nacional; esto se debe a la carencia de una infraestructura económica adecuada, particularmente en las provincias del Callejón de Conchucos y en menor medida en las provincias del Callejón de Huaylas, así como al altísimo nivel de corrupción que se asentó entre las autoridades del gobierno regional de Áncash justamente a partir del 2007 con el gobierno del señor César Álvarez.

\section{e. Exportaciones y Crecimiento Econó- mico}

La elasticidad-exportaciones FOB del PBI (Eex) para la región Ancash es nula, mientras que para el país es 0,89 ; estos resultados nos indican el nulo impacto que han tenido las exportaciones FOB ancashinas sobre el PBI de la región Ancash en comparación con el impacto que han tenido las exportaciones FOB del país sobre el PBI nacional; las razones son las mismas que en el caso referido a las finanzas. Es decir carencia de Infraestructura Vial y Corrupción de parte del Gobierno Regional.

\section{$\mathrm{E}_{\text {exportación }}=\left(\frac{\triangle P B I}{P B I}\right) /\left(\frac{\Delta \text { Exportaciones }}{\text { Exportaciones }}\right)=\varnothing$}


Tabla 2.

Exportaciones y PBI de la Región Ancash y a nivel Nacional Fuente: BCR; Cuánto; INEI; cálculos del autor.

\begin{tabular}{|c|c|c|c|c|c|c|c|c|c|}
\hline & \multicolumn{8}{|c|}{ PBI (millones soles 2007) } & \multirow[t]{2}{*}{ Promedio } \\
\hline & 2007 & 2008 & 2009 & 2010 & 2011 & 2012 & 2013 & 2014 & \\
\hline Áncash & 17090 & 18445 & 18002 & 17748 & 17884 & 19563 & 20275 & 17801 & \\
\hline Nacional & 319693 & 348923 & 352584 & 382380 & 407052 & 431273 & 456159 & 466880 & \\
\hline \multicolumn{10}{|c|}{ PBI tasa crecimiento } \\
\hline & 2007 & 2008 & 2009 & 2010 & 2011 & 2012 & 2013 & 2014 & \\
\hline Áncash & - & 7,9 & $-2,4$ & $-1,4$ & 0,8 & 9,4 & 3,6 & $-12,2$ & 0,8 \\
\hline \multirow[t]{3}{*}{ Nacional } & - & 9,1 & 1 & 8,5 & 6,5 & 6 & 5,8 & 2,4 & 5,6 \\
\hline & \multicolumn{8}{|c|}{ Exportaciones FOB (millones US\$) } & Promedio \\
\hline & 2007 & 2008 & 2009 & 2010 & 2011 & 2012 & 2013 & 2014 & \\
\hline Áncash & 4006 & 3974 & 2916 & 3922 & 4506 & 4865 & 4317 & 3246 & \\
\hline Nacional & 28094 & 31018 & 27071 & 35803 & 46376 & 47411 & 42861 & 39533 & \\
\hline \multicolumn{10}{|c|}{ Exportaciones FOB tasa crecimiento } \\
\hline & 2007 & 2008 & 2009 & 2010 & 2011 & 2012 & 2013 & 2014 & \\
\hline Áncash & - & $-0,8$ & $-26,6$ & 34,5 & 14,9 & 8,0 & $-11,3$ & $-24,8$ & $-0,9$ \\
\hline Nacional & - & 10,4 & $-12,7$ & 32,3 & 29,5 & 2,2 & $-9,6$ & $-7,8$ & 6,3 \\
\hline
\end{tabular}

Evolución de las Exportaciones de la Región Áncash

Tal como se aprecia en la tabla $\mathrm{N}^{\circ} 3$, las exportaciones FOB de la región Áncash muestran una tendencia creciente con altibajos el 2009 y en el bienio 2013-2014; estas exportaciones se elevaron de manera impresionante desde los US\$ 681,5 millones el año 2003 hasta los US\$ 4000 millones en el bienio 2007-2008; luego cae el 2009 hasta los US\$ 2 916,2 millones, es decir en más de US\$ 1000 millones; felizmente durante el trienio 20102012 estas exportaciones recuperaron y superaron el nivel que tenían el año 2008; así, para el 2012 las exportaciones ancashinas alcanzaron los US\$ 4 865,2 millones; finalmente durante el bienio 2013-2014 se redujeron estas exportaciones hasta un nivel (US\$ 3 246 millones) algo superior al del año 2009 (US\$ 2 916,2 millones).

Tabla 3.

Evolución de las Exportaciones de la Región Áncash Fuente: Banco Central de Reserva del Perú.

\begin{tabular}{ccccccccccccc} 
& \multicolumn{10}{c}{ Millones US\$ } \\
& 2003 & 2004 & 2005 & 2006 & 2007 & 2008 & 2009 & 2010 & 2011 & 2012 & 2013 & 2014 \\
$\begin{array}{c}\text { Tradicio- } \\
\text { nales }\end{array}$ & 669,5 & 1563,6 & 2311,3 & 3228,1 & 3884,4 & 3828,2 & 2820,6 & 3810,1 & 4350,6 & 4688,5 & 4164,9 & 3127,0 \\
\hline No-trad. & 12,0 & 19,1 & 84,8 & 135,3 & 121,2 & 146,1 & 95,6 & 112,2 & 155,1 & 176,7 & 152,4 & 119,0 \\
\hline Total & 681,5 & 1582,7 & 2396,1 & 3363,4 & 4005,6 & 3974,3 & 2916,2 & 3922,3 & 4505,7 & 4865,2 & 4317,3 & 3246,0 \\
\hline
\end{tabular}




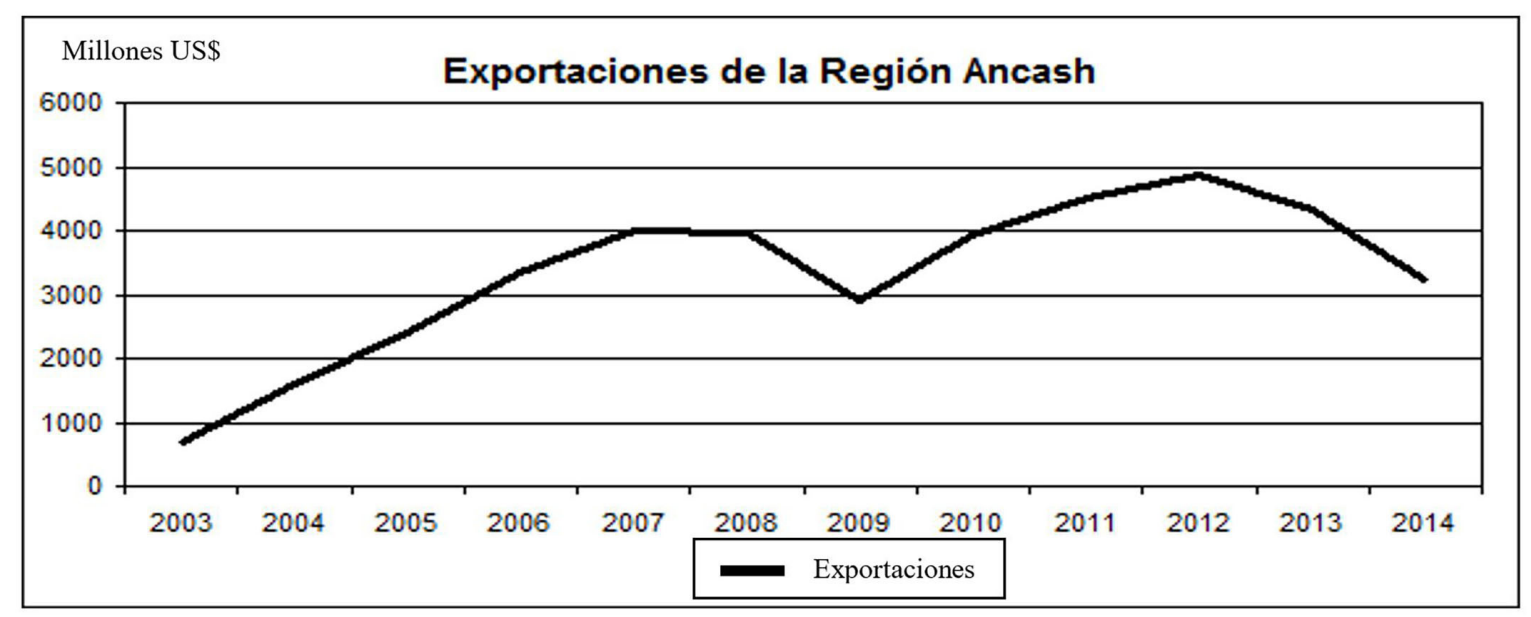

Figura 2. Evolución de las Exportaciones de la Región Áncash, 2003-2014

Fuente: Elaboración propia

Exportaciones Tradicionales más importantes de la Región Áncash

En la Tabla 4, se puede apreciar que dentro de los productos mineros de exportación de la región Áncash resalta la exportación de cobre cuya importancia dentro del total de las exportaciones de la región se eleva desde el 48,6\% (casi la mitad del total) el 2003 hasta el 68,5\% (más de $2 / 3$ del total) el 2014, pasando desde los US\$ 331,2 millones el 2003 hasta los US\$ 2 223 millones el 2014, es decir elevando sus exportaciones cupríferas en 6,7 veces en 11 años; el segundo producto minero en importancia es el zinc que el 2003 tenía una participación dentro del total de las exportaciones regionales del $19,5 \%$, mientras que para el 2014 esta participación había caído hasta el 10,2\%; otros productos mineros que exporta la región son el oro, el molibdeno, el plomo y el tungsteno en ese orden.

Tabla 4 .

Estructura de las Exportaciones de la Región Áncash Fuente: Banco Central de Reserva del Perú.

\begin{tabular}{|c|c|c|c|c|c|c|c|c|c|c|c|c|}
\hline & 2003 & 2004 & 2005 & 2006 & 2007 & 2008 & 2009 & 2010 & 2011 & 2012 & 2013 & 2014 \\
\hline Tradicionales & 98,2 & 98,8 & 96,5 & 96,0 & 97,0 & 96,3 & 96,7 & 97,1 & 96,6 & 96,4 & 96,5 & 96,3 \\
\hline Azúcar & 0,0 & 0,0 & 0,0 & 0,0 & 0,0 & 0,0 & 0,0 & 0,0 & 0,0 & 0,0 & 0,0 & 0,0 \\
\hline Pesqueros & 30,1 & 21,3 & 14,0 & 8,4 & 10,2 & 12,7 & 17,9 & 15,5 & 9,9 & 14,9 & 10,5 & 12,7 \\
\hline Harina pescado & 23,5 & 16,4 & 11,5 & 6,0 & 7,4 & 7,7 & 14,5 & 12,6 & 7,1 & 9,7 & 8,4 & 8,9 \\
\hline Aceite pescado & 6,6 & 4,9 & 2,5 & 2,4 & 2,8 & 5,0 & 3,4 & 2,9 & 2,8 & 5,2 & 2,1 & 3,8 \\
\hline Mineros & 68,1 & 77,5 & 82,5 & 87,6 & 86,7 & 83,6 & 78,8 & 81,6 & 86,6 & 81,5 & 86,0 & 83,7 \\
\hline Cobre & 48,6 & 52,7 & 47,4 & 57,4 & 51,2 & 53,2 & 51,3 & 52,8 & 65,3 & 67,1 & 70,5 & 68,5 \\
\hline Oro & 0,0 & 17,3 & 12,2 & 9,6 & 8,6 & 9,3 & 9,1 & 6,6 & 6,2 & 4,1 & 5,1 & 1,7 \\
\hline Zinc & 19,5 & 7,6 & 5,6 & 9,8 & 16,6 & 8,9 & 13,3 & 14,4 & 8,5 & 5,9 & 7,8 & 10,2 \\
\hline Molibdeno & 0,0 & 0,0 & 17,3 & 10,8 & 8,9 & 9,9 & 1,9 & 2,0 & 3,6 & 3,1 & 2,0 & 0,0 \\
\hline Otros (1) & 0,0 & 0,0 & 0,0 & 0,0 & 1,2 & 2,2 & 3,2 & 5,9 & 3,0 & 1,1 & 0,6 & 3,2 \\
\hline No-tradicionales & 1,8 & 1,2 & 3,5 & 4,0 & 3,0 & 3,7 & 3,3 & 2,9 & 3,4 & 3,6 & 3,5 & 3,7 \\
\hline Total & 100,0 & 100,0 & 100,0 & 100,0 & 100,0 & 100,0 & 100,0 & 100,0 & 100,0 & 100,0 & 100,0 & 100,0 \\
\hline
\end{tabular}




\section{DISCUSIÓN}

Durante el trabajo de investigación se encontró que las exportaciones así como de las finanzas en la región Áncash no tuvieron el impacto esperado sobre el crecimiento del PBI regional debido a la carencia de infraestructura económica (red vial), a pesar de estas deficiencias la pobreza durante el periodo 2007-2014, tuvo una reducción de 19,1 percentiles. Sin embargo esta reducción no ha sido homogénea.

La región Áncash muestra 3 zonas marcadamente diferentes en cuanto a sus dotación de infraestructura vial: la costa, el Callejón de Huaylas y el Callejón de Conchucos, siendo la primera zona la mejor dotada vialmente y siendo la tercera zona(callejón de conchucos), la menos dotada de infraestructura vial; esta realidad da lugar a que ni las empresas líderes, es decir las exportadoras, ni la banca tengan como sede a alguna provincia del Callejón de Conchucos, lo cual a su vez crea zonas dinámicas económicamente en la costa así como en el Callejón de Huaylas; finalmente, no es casualidad que la zona del Callejón de Conchucos sea la zona más pobre de la región Áncash encontrándose en esta zona elevados índices de desnutrición crónica alrededor de 14,6\%, y el IDH (Índice de Desarrollo $\mathrm{Hu}$ mano en sus tres dimensiones: salud, educación y nivel de vida digno) es apenas el 0,2874, podemos ver que éste índice está cercano a cero lo que demuestra una calidad de vida deplorable, en contraste con el IDH nacional que en el año 2014 fue de 0,735 y en Lima Metropolitana fue de 0,6787, en el distrito la Molina es 0,7814 ,en el distrito de Miraflores es de 0,7971, y también en el distrito de Magdalena del Mar es de 0,749, todo esto se da en la Región de Lima.
De lo anterior se desprenden las siguientes recomendaciones:

Asfaltar la carretera longitudinal del Callejón de Conchucos y construir carreteras y/o ferrocarriles transversales costa-Callejón de Huaylas-Callejón de Conchucos con la finalidad de integrar territorialmente la economía de la región Áncash; ya se ha mencionado que las redes viales son fundamentales para unir las zonas productivas con los mercados locales, regionales, nacionales e internacionales; asimismo, una red vial adecuada es fundamental para fomentar el turismo interno como receptivo.

Apoyar la agro exportación costeña mediante la modernización del puerto de Chimbote; se espera que la agro exportación del proyecto Chinecas tanto lo de la zona norte y sur de la región Áncash se exporte por este mismo puerto.

Reactivar y poner en valor las tierras del proyecto Chinecas con la finalidad de aprovechar productivamente su disponibilidad de tierras de cultivo y de abundante agua de riego proveniente del río Santa.

Fortalecer el sistema financiero de la Región Áncash, elevando la profundización financiera (colocaciones/PBI), a través de la mejora sustancial de la infraestructura económica(red vial, dotación de energía eléctrica, agua potable, disponibilidad de Internet con banda ancha, aeropuerto, puertos) que facilite la inversión privada y en particular la de la banca múltiple así como de las micro finanzas, sobre todo en las provincias del Callejón de Conchucos, en vista que en estas provincias, el sector privado no ha recibido ningún monto de crédito.

\section{REFERENCIAS BIBLIOGRÁFICAS}

Argandoña, A. (2007). La empresa y el crecimiento económico. Barcelona: Universidad de Navarra.

García, J. \& Céspedes, R. (2011). Pobreza y Crecimiento económico - tendencias durante la década del 2000. Lima: Banco Central de Reserva del Perú.

García, R. (2017/10/13). CEPAL- Brecha de desigualdad impide el desarrollo del Perú. Diario Exitosa, (sección Economía) p.14

Ohlin, B. (1966). Teoría Heckscher-Ohlin. Filadelfia: Havard Economic Press.

Nuñovero, L. (2011). La Lucha contra la pobreza en los confines del Derecho y los Derechos Humanos. (Tesis para optar el título de abogada). Pontificia Universidad Católica del Perú, Lima.

Ricardo, D. (1817). Principios de Economía Politica y Tributación. Barcelona: Ediciones Orbi. S. A.

Schumpeter, J. (1911). Teoría del Desarrollo Económico. Cambridge: Harvard University Press.

Smith, A. (1776). Investigación sobre la Naturaleza y Causa de la Riqueza de las Naciones. Barcelona: Ediciones Orbi. S. A. 